This is an Accepted Manuscript of an article published by Elsevier in The Internet

and Higher Education on April 2018, available online:

https://doi.org/10.1016/j.iheduc.2017.11.001

Recommended citation: Pacheco, E., Lips, M., \& Yoong, P. (2018). Transition 2.0: Digital technologies, higher education, and vision impairment. The Internet and Higher Education, 37, 1-10. doi: https://doi.org/10.1016/j.iheduc.2017.11.001

\title{
Transition 2.0: Digital technologies, higher education, and vision impairment
}

\begin{abstract}
This article introduces Transition 2.0, a paradigm shift designed to study and support students with disabilities' transition to higher education. Transition 2.0 is the result of a qualitative study about how a group of young people with vision impairments used digital technologies for their transition to university. The findings draw from observations, a researcher diary, focus groups, individual interviews, and data from social media. The article discusses a conventional view of transition, referred to here as Transition 1.0, which has dominated disability-related research and service provision in higher education. It counters this view by further developing the conceptual framework for Transition 2.0. The findings expand current conceptual approaches to transition by incorporating in the analysis the role played by digital tools such as social media and mobile devices. They also provide a new lens through which to study and understand student engagement in higher education.
\end{abstract}

Keywords: transition, disability, digital technologies, social media, mobile devices, higher education. 


\section{Introduction}

The transition to university is a critical event in the life of young students to the extent that it has an impact on their decision to continue or leave higher education (Tinto, 1993). Research on this matter is important because it can inform the development of approaches and services to support new students (Upcraft, Gardner, \& Barefoot, 2004) and help to address the perennial challenge faced by tertiary institutions regarding student retention and engagement (Kuh, Cruce, Shoup, Kinzie, \& Gonyea, 2008). With the widespread use and increasing sophistication of digital technologies and their integration in various aspects of higher education, researchers have paid attention to the impact of these tools on teaching and the learning experience of students (Selwyn, 2007). Some, for instance, have looked at first-year students' general use of technology in the university setting (Kennedy, Judd, Churchward, Gray, \& Krause, 2008), and how an e-mentoring programme affected new students' peer support (Risquez \& Sanchez-Garcia, 2012).

While there is some interest in transition to higher education in relation to the role played by digital technologies, the literature, however, has focused on non-disabled students. Our understanding of the experiences of specific groups such as students with impairments is still insufficient. Most research on disability has centred on the role of assistive technologies for the academic functioning and adjustment of these students but has neglected the impact of other emerging technologies.

Research on students with disabilities is particularly relevant today because there is a trend of growing numbers of these young people pursuing personal development and independence through higher education (Ebersold, 2008). However, for students with disabilities, transition can be a more challenging and stressful experience due to the barriers imposed by their impairments (Kochhar-Bryant, Bassett, \& Webb, 2009). Evidence shows that these students are more likely to quit university compared with their non-disabled peers (Bardin \& Lewis, 2008). Even those who persist spend more time studying at university before graduation (Caton \& Kagan, 2007). Thus, we not only need to study university transition and disability but also incorporate in the analysis the role played by digital technologies in order to provide appropriate resources and support for a successful transition of these students.

This article contributes to the understanding of transition to university in the context of disability - which has largely ignored the role of emerging digital technologies. The underpinning research question of the study was, "How do students with vision impairments use digital technologies for their transition to university?" Based on the research findings, the article develops Transition 2.0 as a new paradigm to study and support students with vision impairments' transition to higher education.

\section{Background}

\subsection{The conventional view: Transition 1.0}

The study of transition to university has been dominated by a conventional view, which hereafter we refer to as Transition 1.0. We argue that Transition 1.0 has focused on the adjustment of the student within the tertiary setting (Terenzini, Springer, Yaeger, Pascarella, \& Nora, 1996). Transition is a period of psychological and academic changes for the student (Terenzini et al., 1996), who also has to deal with an unknown university environment where there is no longer a dedicated and personalised disability support system available (Janiga \& Costenbader, 2002). The student not only feels alone and stressed but also has to rapidly learn the skills for independent learning (Kochhar-Bryant et al., 2009). In Transition 1.0, students with disabilities are accommodated to fit into the demands of the tertiary setting, especially in regard to managing academic responsibilities (Fowler, Konrad, Walker, Test, \& Wood, 2007). Support to ease the transition experience has centred on compensating and/or ameliorating the impact of their impairment through the provision of a range of specialised services and resources (Getzel \& Wehman, 2005), so students with impairments can adjust to university (Kochhar-Bryant et al., 2009). 
In Transition 1.0, assistive technologies play a primary role in compensating for the impairment of the students (Michaels \& McDermott, 2003). Assistive technologies are defined as "equipment, or product system, whether acquired commercially off the shelf, modified, or customized, that is used to increase, maintain, or improve functional capabilities of individuals with disabilities" (Scherer, 2002, p. 1). These tools support students' academic duties and performance (Stumbo, Martin, \& Hedrick, 2009). For example, closed-circuit television systems (CCTV), which have a video camera connected to a monitor, help students with vision impairments to enlarge the size of text and images from books and other courserelated material and to adjust their colour and background if needed (Presley \& D'Andrea, 2009). Similarly electronic Braille and screen magnification software help these students to read course material making it easy to access texts from newspapers, journals and books and graphical information such as pictures and mathematical equations (Presley \& D'Andrea, 2009).

Transition 1.0 also involves the opportunities brought by the inception of the Internet and the increased use of personal computers. For students with vision impairments these kinds of technological tools have facilitated, for example, access to information and communication (Kelly \& Wolffe, 2012). The use of a personal email service, for instance, makes it easier to be in contact with friends and relatives, overcoming issues of distance and time. Similarly, a personal computer adapted with other assistive technology allows the student to enlarge the fonts or change the brightness on the screen, making course material readable. Despite these benefits, technological developments have also raised concerns about accessibility and usability (Paciello, 2015). Some also argue that digital technologies are disabling (Goggin \& Newell, 2003) and/or creating a disability divide (Dobransky \& Hargittai, 2006).

The adoption of social media and the constant advances in mobile devices have generated research interest on the implications of these tools for higher education. Evidence has already shown how non-disabled students have incorporated digital tools for their learning and adjustment to the tertiary setting (DeAndrea, Ellison, LaRose, Steinfield, \& Fiore, 2012; Gikas \& Grant, 2013). However, our understanding of how young people with disabilities, such as those with vision impairments, use digital tools for transition is limited to research that has looked at the use of desktop computers and non-interactive websites (Zhou et al., 2012), or mobile applications designed for school children with impairments (Fernández, Rodríguez, Rodríguez, \& Martínez, 2013).

To sum up, Transition 1.0 centres on the changes experienced by the students at university at an individual level and the support provided to them to accommodate and/or compensate for the impact of their impairments. To a large extent, in Transition 1.0 the students make sense of their transition on their own and the use of technological tools, particularly assistive technologies, is fundamentally encouraged to emphasise the transition experience as an individual journey.

\subsection{The theory of departure}

Our argument about Transition 1.0 is accompanied by several attempts at theorising this period of change for young people, some of which date back more than forty years (see Bean, 1980; Cabrera, Nora, \& Castaneda, 1993; Spady, 1971). However, Vincent Tinto's (1993) theory of student departure has been the most used in research in higher education, and it is the one that best embodies the idea of Transition 1.0. Tinto's theory has been applied in studies about students with disabilities' transition to university (see Belch, 2004; Duquette, 2000; Wessel, Jones, Markle, \& Westfall, 2009). The theory outlines the complex process of student integration and the crucial role that the social and academic systems of the tertiary institution play in the university experience. Both systems continually influence students and modify their original goals and commitments and thus lead them to either study completion or early departure (Tinto, 1993). The academic system refers to the formal education of students, taking place not only in the classroom but also in other tertiary environments such as laboratories and involves various faculty and staff whose primary responsibility is the education of students (Tinto, 1993, p. 106). On the other hand, the social system involves the many members of the tertiary institution, especially the students. It is shaped by social interactions among students, faculty and support staff which mainly happen outside the formal 
academic system of the tertiary setting, for instance, university halls, cafeterias and student clubs (Tinto, 1993).

In order to persist in higher education, the students must pass three stages: separation, transition, and incorporation (Tinto, 1993, p. 94). Separation is an isolating and stressful, if not a temporarily disorienting, experience. Students have to "disassociate themselves, in varying degrees, from membership in the past communities, most typically those associated with the local high school and place of residence" (Tinto, 1988, p. 95). The second stage, transition, refers to a critical and most challenging period of passage between the old and the new and occurs during and after the stage of separation (Tinto, 1993, p. 97). During transition the students "have not yet established the personal bonds which underlie community membership. As a result, they are neither bound strongly to the past, nor firmly tied to the future" (Tinto, 1988, p. 444). In the third stage, incorporation, the students are looking for integration and membership in the tertiary institution (Tinto, 1988). Social interactions are the primary means for achieving incorporation. Those who are unable to develop such interactions are likely to experience integration failure, including a sense of isolation which could cause withdrawal (Tinto, 1988).

Despite being largely used in the study of transition to university, authors have also challenged Tinto's theory on the grounds that it does not consider students' cultural differences. Tierney (1992) argues that Tinto's theory not only suggests abandonment of ethnic identities among minority student groups but also inserts them into a "dominant cultural frame" (Tierney, 1992, p. 611). He argues that the model should include a cultural integrity approach based on concepts such as cultural capital and habitus. A similar opinion is shared by Guiffrida (2006) who criticises the lack of a cultural domain in Tinto's model and suggests that conceptual tools such as cultural norms and motivational orientation could help in that regard. Others (Neumann \& Finaly-Neumann, 1989; Webb, 1988) question the utility of Tinto's theory in the context of students' later years of university experience or in tertiary settings such as two-year community institutions.

\subsection{Towards Transition 2.0}

The limitations of the theory of departure are more apparent today due to the rapid development and widespread use of digital technologies. When Tinto developed his theory, digital technologies such as the Internet were not in the stage of commercial diffusion and they were only used and accessed by very few people (Bell, 1999). Even computer-mediated networks were not widely used in the tertiary environment. Nowadays, digital tools are ubiquitous and young people are argued to be digital natives because they are growing up with technologies such as social media, smartphones, laptops, tablets, and computer and console games (Prensky, 2001). Digital technologies are not only changing the way education is delivered but also how students learn, communicate and interact in the tertiary setting (Ellison, Steinfield, \& Lampe, 2007). Clearly, digital technologies are the missing component in current conceptual analysis and development of frameworks/models of transition to university. Studying transition without considering the enabling roles of digital technologies for collaboration, learning, and support, among others, limits the understanding of this and other matters such as student retention and participation. Tinto's theory has been a valuable approach for scholars; however, research on transition can no longer ignore the relation between students' experiences of transition, including those with impairments, and the way they use and adapt actively technological tools. As digital technologies play a critical role in young people's highly connected lives (Boyd, 2014), there is a need for a new approach about transition that incorporates the dynamic interaction between young people and tools such as social media and mobile devices. This paper addresses the challenge in the context of students with vision impairments by presenting Transition 2.0 and developing a conceptual framework that includes the role of new technologies on the way new students make sense of transition to higher education. 


\section{Research Design}

The purpose of the study was to gain in depth understanding of the way a group of students with vision impairments used digital technologies for their transition to university. The study applied a qualitative approach because we sought to comprehend the social and cultural context of the participants in regard to their transition and the use of digital technologies, in other words what they say and do (Myers, 2013). In addition, qualitative inquiry allows flexibility (Creswell, 2003). By using a qualitative approach, we were able to use an open research framework which was adjusted or refined when needed.

Action Research (AR) was the chosen research method for this study. AR seeks to "solve current practical problems while expanding scientific knowledge" (Baskerville \& Myers, 2004, p. 329). As transition is a more challenging and stressful experience for students with disabilities, we used AR not only to expand current knowledge about this topic but also to support the participants to manage the challenges of their transition. We did it by implementing blended interventions. In addition, AR is a research method that is suited to the study of the interaction between people and technology (Baskerville \& Myers, 2004). The use of AR also allowed us to enhance involvement and collaboration with and among the participants which helped them to make sense of and manage their transition experience.

Blended interventions were implemented during the two AR cycles of this study. In the first cycle, we set up a website called Goingtouni via the Moodle platform. We provided transition-related information and links to the participants to help them identify potential transition challenges. Although the resources in Goingtouni were used by all the participants, we were unable to encourage interaction and collaboration among them. Reflecting on the limited impact of our intervention, in the second AR cycle we decided to incorporate focus groups, which also worked as group support meetings. Through the meetings, the participants shared their transition experiences, provided support to each other and developed friendships. Following a suggestion from the participants, another intervention involved setting up a Facebook closed group page which complemented participants' peer support online.

\subsection{Research participants}

Research participants were selected purposefully. In qualitative research, sampling is purposeful because it typically focuses on relatively small samples. More important, rather than formulating empirical generalisations, which is a goal of quantitative research, qualitative inquiry's goal is in-depth understanding of the topic of study through information-rich cases (Patton, 2002, p. 230). It strategically samples participants that are relevant to the research question(s) of the study (Bryman, 2008). As our goal was to explore and gain deep understanding of participants' transition experiences and their use of digital technologies, purposeful sampling was the appropriate approach. Our strategy for selection of the participants was based on what Patton (2002) calls homogeneous samples, which centres on describing "some particular sub-group in depth" (p. 235). This approach was useful for our study as students with vision impairments represent a sub-group within the wider disability community at Victoria University of Wellington. Because of their limited sight, these students have specific needs and may experience transition challenges differently compared with their peers with other impairments. Thus, by studying this "homogeneous" sub-group, we were able to explore in more detail participants' experiences of transition to university.

A total of 19 participants took part in the study at different levels. They were undergraduate students, aged from 18 to 24 years old, first enrolled at the University in trimesters 1 and 2, 2012, and trimester 1, 2013. They were enrolled in subjects such as education, law, marketing, history, art history, geography, and psychology. Over a third of the participants came from Wellington and the rest from different cities and rural areas of New Zealand. In terms of schooling background, the participants came from varied educational systems such as special education schools and boarding schools but the majority had studied in public schools where they had received dedicated teaching support. 
The study was conducted at Victoria University of Wellington. The University has 21,000 students approximately. In the last few years the number of students with impairments registered with the Disability Services has steadily grown. In 2015, for instance, 1184 students were registered with the unit while 1372 did so in 2016. All the participants were registered with the Disability Services. The unit provides prospective and new students with impairments with transition-related advice and services such as note takers. It also guides and trains them in the use of assistive technologies based on the specific disability needs of the students. It liaises with Course Coordinators and lecturers to arrange the delivery of electronic material to students in advance of lectures. One of the authors worked for the unit as a volunteer and a part-time research staff member during the study. Once at university, students with impairments have access to a dedicated space which is equipped with specific assistive technologies (e.g. a closedcircuit television system and computers with screen magnifier software). Like the rest of the students, students with disabilities also have access to student email, computer rooms, Wi-Fi, printing and Blackboard, the University's course management system.

\subsection{Data collection}

Data gathering began before the start of the academic trimester, when the participants were still prospective students, and continued until the first weeks of trimester 2. Data collection techniques included observations, a researcher diary, online tools, focus groups, data from social media, and semi-structured interviews. These data were analysed inductively. The use of different qualitative techniques allowed the gathering of rich information at different stages of participants' transition experience. Observations were unobtrusive and conducted, in the majority of cases, a few months before the participants started studying at university. Once potential participants were contacted with the help of the Disability Services, we asked for permission to attend their individual meetings with a Disability Advisor. Our role was to observe and take notes of participants' early transition concerns and support needs which included managing academic duties, finding adequate accommodation and transport, and learning how to navigate around the University's physical environment. The observations also provided data about participant's use of devices such as smartphones, tablets, and assistive technologies during their meetings. To manage the potential risk about our own views and personal beliefs impinging upon observations, we followed Patton's (2002) suggestion for empathetic neutrality, which means to care about the participants being studied but be neutral about the content they reveal (Patton, 2002, p. 569). Another approach to manage observer's bias was triangulating varied sources of data at different stages of the study (Bryman, 2008). Observation data were complemented with the use of a researcher diary which was employed to keep records, facilitate retrospective analysis, recall past thoughts and events, and evaluate the outcomes of the research (Borg, 2001).

Data from online tools were collected via the Goingtouni website and a Facebook closed group page. As previously mentioned, the website helped to collect data about participants' early transition experiences. The use of Facebook was suggested by the participants. Data from Facebook was collected in the form of comments, "likes" and the "seen by" feature on Facebook. While participants' online interaction via Facebook was mainly private, we managed to encourage some online group conversation in which the participants shared their personal experiences of transition and use of social media and smartphones in that respect.

Three focus groups were conducted with a group of 6 participants. While there is not agreement about the ideal size of a focus group (Liamputtong, 2011), some recommend meetings comprising of 4 to 6 participants to allow open and active discussion (Smithson, 2008). Because limited online interaction and participation was obtained via the Goingtouni website, the focus groups were an adjustment to the initial research plan and added to our AR interventions - the other AR interventions were the Goingtouni website and the Facebook group. Focus groups were originally set up for 50 minutes, but due to participants' active engagement the meetings lasted an hour and a half. We managed not only to collect rich data but also help participants to discuss transition challenges openly and build new social connections. The focus 
groups allowed us to understand how the perceptions of the participants regarding their transition evolved through the first weeks of the academic trimester and the way they used ICT tools and services provided by the University (e.g. Blackboard, eBooks) for their learning. Semi-structured interviews were also conducted with 10 participants after they completed their first academic trimester at university. In the interviews the participants evaluated their transition experience and the way digital technologies were used to manage it.

\subsection{Data analysis}

An inductive approach was used for data analysis. Inductive analysis is "making sense of data" (Lincoln \& Guba, 1985, p. 202). It is an approach through which patterns, categories, and themes are built from the bottom up, by organising the data into increasingly more abstract units of information (Creswell, 2007, p. 38). By adopting an inductive approach, the findings of the study are data-oriented (Bryman, 2008). In other words, instead of confirming a hypothesis and theoretical assumptions, the concepts, categories and conceptual framework developed in this study were based on what the data was revealing. Transcripts were read and analysed several times to identify themes, to refine interpretations, and to allow new categories to emerge. From Tinto's theory, we used his arguments about the academic and social systems to inform our identification and analysis of transition challenges affecting the participants.

Data analysis started in parallel with data collection. It was an ongoing and iterative process that helped to refine the interpretation of the findings. It was ongoing because it took place throughout the different stages of the study and it was iterative because our interpretation of the data was refined several times as more data were collected and we reflected in more depth about their meaning.

To ensure the quality and credibility of the study, we followed Lincoln and Guba's (1986)) advice for assessing trustworthiness and authenticity in qualitative research. We triangulated data by collecting rich information from different sources such as focus groups, interviews, observations, a researcher diary, and social media at different stages of participants' transition experience. During data analysis, we also looked for discrepant evidence and negative cases that did not fit the pattern (Patton, 2002) which helped us to challenge our interpretation of findings. We also engaged in member checking. At the beginning of each focus group meeting, for example, we prepared and presented to the participants a brief synopsis about what we thought were the key ideas, issues and lessons from the previous session. The participants also had an opportunity to look at the transcripts of their interviews. In addition, we prepared and shared with them an online video on YouTube with the main findings of the study. We did so because the participants commented that when reading the transcripts their limited vision blurred and they got easily tired as well. We tried to avoid stressing the participants.

\section{Findings and Discussion}

\subsection{The stages of transition for students with vision impairments}

The findings allowed us to identify that students with vision impairments go through five distinctive and overlapping stages during their transition to university, in contrast to Tinto's (1993) three stages. The stages we identified are: exploring university as an option, discovering university life, coping with turning points, readjusting the transition experience and settling in at university. The findings show that while some students were in the midst of the discovering stage - still learning about the university's academic system and physical environment - they were also in the stage of coping with turning points - being unable to make new friends, for example. An explanation of these transition stages and how digital technologies were used to manage transition challenges is presented below.

\subsection{Exploring university as an option}

Exploring is a pre-entry stage. Students reflect on and decide about pursuing tertiary studies when still in high school. University is seen as a pathway for personal development and a passport for independent life. Despite having priorities and set goals students still need support. They seek information, and look 
for advice. They ask family, friends and other contacts about their university experiences and what university life looks like. They are aware that their impairment will be one of the main challenges for their university journey:

It [my vision impairment] is definitively a barrier. The simple fact that I can't pick up a text and read it does have a huge impact on me...I have always done things to compensate. (VIS-GE)

During the meetings with their Disability Advisers, we observed a few participants using their mobile phones to save information. We also saw some of them using assistive technologies such as a portable electronic magnifier to compensate for their impairment. In the interviews, they mentioned that in the exploring stage they looked at the University's website and/or YouTube for information about specialised support, accommodation and university entrance requirements. These actions were supported by their use of personal email to communicate with university staff:

I looked out in the website and I got in touch with the Admission Office, I think, and I discussed with them the fact that I was vision impaired and I wanted to find out what support is available for people with disabilities at Victoria University before I definitively came here. (VIS-CA)

Several participants visited the Goingtouni website on Moodle before starting their university journey. They were interested in finding information about degree and course planning and watched the various YouTube videos posted on the section about transition to university. One participant commented on the usefulness of having information available online via the Goingtouni website during the exploring stage:

All the information that you posted there was all relevant, was all to do with university and transitioning and everything disability-related, not mattering if it is an intellectual, visual and any other disability. (VIS-JO).

One participant commented that the amount of transition-related information available online is overwhelming and thus difficult to digest. However, it is more convenient than reading paper-based documents. Her comment was in the context of her experience with the Goingtouni website:

I think...[Goingtouni] has everything you need because usually we have to look at different websites or get booklets, different booklets, or find out all that stuff but it pretty much has a lot of stuff I was looking for last year on the website so I was like: this is cool. (VIS-GR).

\subsubsection{Discovering university life}

The discovering stage refers to the students' first real encounter with university life. It starts from day one at university. The students feel anxious and lost and are concerned about having timely and adequate support in place (e.g. a note-taker in their lectures). In this stage, the students experience the change from high school to university and the need to become an independent learner. One participant described the change in this way:

It [university] is so much different from high school. In high school they [teachers] teach you how to take in the information as well. Whereas here, they (lecturers] just blast it at you and then you go to the tutorial and they [tutors] kinda blast you with more stuff and then you are reading a book. I wish I would not finish high school because I don't know how to process information a little bit. (VIS-CA).

Digital technologies were used to deal with the first transition challenges that emerged at the beginning of the academic trimester for example the physical environment of the University. The students, for example, 
used a campus map in PDF format emailed to them or retrieved from the university's official website. Alternatively, they used the Google Maps application on their smartphones for campus navigation. In relation to the academic challenges, the students brought their laptops to the lectures, and in some cases, digital voice recorders and cameras, to support vision compensation and their learning experience:

I have OpenBook [a scanning and reading program], ZoomText [a magnification program] and I've also got a recorder to take to lectures as well... OpenBook and the recorder do help. I like OpenBook because I can look at the stuff that is there anyway and even if I am not reading it following it is enough. (VIS-CA)

Most participants brought their own laptops or tablets to classes. This action of the participants to support their learning and academic matters is in line with a tendency among university students in general who are using their personally owned portable devices to engage inside lectures (Gikas \& Grant, 2013). Several participants also commented on the utility of their personal email to receive disability support and course-related information and updates. The participants who had the support of a note taker also pointed out how their learning experience was improved by regularly receiving lecture notes attached to emails:

They [note takers] email me notes weekly from the classes because it is hard to write notes for myself sometimes and having someone else in the class doing it for me really helps. I am like: "oh, that's what they mean by that". (VIS-MO).

The students also used their social media profiles and their smartphones to receive updates from their university halls of residence. They also used their laptops, tablets and/or smartphones to access bus timetable information and plan their trips to university and vice versa:

I learned to lookfor it [bus timetable] at home. I got my computer set to really large fonts so I can read it. So, I learned to do it at home before I take the bus. I can make my internet screen bigger so it makes it easier to read. (VIS-CA)

\subsubsection{Coping with turning points}

The third stage of Transition 2.0 finds the participants identifying and coping with turning points. Turning points are situational life events and/or personal, subjective experiences and realisations that represent a significant shift regarding the self, identity and the meaning and/or direction of a person's life (King et al., 2003). The findings of this study show that turning points can arise at any moment of the academic trimester and are not always caused by a negative event or experience. The main causes of turning points were events related to the academic system of the university (e.g. writing assignments, the amount of course-related readings) and social connections (e.g. difficulties making new friends). For a couple of participants experiencing a turning point was related to the idea of quitting university:

You want to quit university every day. I am being honest. It [transition to university] has its ups and downs. When you have a lot of work to do, you just don't want to do anything. (VIS-JO)

Digital tools played a supporting part in participants' attempts to manage academic-system turning points. Most participants mentioned the online forum on Blackboard, the university's course management system, as one of the tools that they used to seek and share information, and to collaborate and work with their peers. Although some of them struggled with the platform at the beginning, once they were used to it Blackboard became the primary source of academic information and resources, and study-related online interaction. One participant, who was in trouble after failing two of her assignments for the same course, commented that she used Blackboard's online forum to post questions and receive feedback from her classmates about writing assignments. 
Another participant commented she was pleased about the way university teaching staff used social media to encourage collaboration among students. Closed groups were set up on Facebook by her lecturer or, in other cases, by class representatives. Being able to "talk with other students" (VIS-CA) via social media was helpful for this student, especially when she was struggling with a research report. The online group set up for this study via Facebook was also used by the students to cope with academic turning points. Information and links we posted on the group page, as part of our AR interventions, took into account the concerns mentioned by the participants in the focus group meetings:

I looked at all your posts and I was like 'oh yeah, this is helpful'. I always used everything you posted. I always knew when you posted something because I got notifications saying "[researcher] has just posted on Goingtouni” and then "oh, OK, what's up this time" and I just had a look. I heard about most stuff you posted but I didn't know where to look for it. It was very useful to have the page. (VIS-MO)

Digital technologies also supported the need for communication and interaction of the participants with their social connections. During the coping with turning points stage, they referred to existing social connections for emotional support and advice. Tools such as Skype, Facebook, texting and instant messaging complemented face-to-face communication and allowed the students to keep in touch with their families, high school friends and university peers. However, the challenge for most participants was how to make new friends in a still unknown university environment. One of them commented that she wanted to drop out of university because she was unable to make new connections and felt isolated. During the focus groups this student met other participants. She coped with the isolation and complemented new social connections with the use of digital tools:

I actually made friends with a lot of them [participants] on Facebook and we actually talk quite often now. I talk with X a lot. He likes me on Facebook all the time. I talk with a lot of them. I had never met them outside of the group. I made new friends through the group and it was very helpful just asking people in the group about stuff (VIS-MO).

\subsubsection{Readjusting the transition experience}

After coping with turning points the students rethink and make changes that not only affect their transition but also their university experience as a whole. While in the preceding transition stages the participants have been, little by little, refining their understanding of the transition to university, in the readjusting stage they obtain a more straightforward and enriched picture of it. The impact of turning points triggers such understanding. In this study, changes were related to the academic system. In general, the participants decided on new directions or goals that included dropping papers, changing their enrolment status to parttime or changing their major in the next trimester. In some cases, they reaffirmed previous goals. The readjusting stage reflected the commitment of the students to their university-related long-term goals and personal development. Interestingly, while dropping out of university was considered by a couple of participants as an immediate response to turning points, none of them decided to leave university:

I'm doing two papers this trimester which is probably what I should have done in trimester 1 just to ease myself into university. (VIS-GR).

The participants used digital technologies to search for information and make informed decisions. Some participants commented that they accessed Victoria University's website and looked for information about other study options as well as administrative procedures to change their degree and/or courses. They used the website to find out the requirements of the courses they planned to enrol in. The participants were also able to access downloadable forms and contact information of pertinent university staff. Changes of degree, major or enrolment status were also possible online via myVictoria, the university's web portal. 
During the individual interviews, the participants did not report any accessibility issues with the university portal:

I mainly go to the normal university site and I just use that when I want to find something. I type on the tab search and it comes out straight away. It is convenient and very helpful. (VIS-JO)

Social media tools were another medium that supported students' search for information during the readjusting stage, e.g. the Facebook group set up for this research. In the last weeks of the academic trimester we re-posted links and information from the University's Facebook page to remind the participants about some deadlines such as course change applications. Some students commented that the re-posts were useful and helped them to realise that the University also had an official page on the social media platform which they started following too. Those participants who came from other regions used their smartphones and Skype to tell their parents about their decisions and received advice and support.

\subsubsection{Settling in at university}

In the settling-in stage the students feel more familiar and in control of their transition experience. Although transition challenges are still present they are perceived as manageable. The students are more confident and secure about their university experience but they are also aware that they still need support.

When we met the participants at the start of their transition they were feeling stressed and alone. A few months later, during the interviews, we found that they felt more in control of their transition.

Ifeel better now. I am in second trimester and my grades havejumped a lot. I wouldn't say they are pretty easy. I just get used to the way the lectures and assignment work. When I first came I was like "wow, what's happening?", "I did not catch that, what do I do?" but now I am more than adjusted; I know how to do [things] properly. (VIS$\mathrm{MO})$

Overall, the participants perceived themselves as independent young adults:

I think I have gained that notion of independence; it is the concept, you know, "oh, I need to go to the shops I just walk out the door and go over". It is not "I wait for mum to get the car, swift and go". It is that notion that I am now in charge, I am the master of my destiny...I would say. (VIS-GE)

The participants evaluated the role of digital technologies in their transition experience and, as one participant concluded, these tools are "one of the biggest helps out there for anyone with a disability" (VIS- JO). For some participants, a transition scenario without digital tools was unimaginable. One student was categorical in this respect when she highlighted that she "will be lost without it [technology], especially my laptop" (VIS-CA). Just as for other participants, for her it was critical to have online access to course material.

Digital tools also played a role regarding participants' relationships with strong ties (Putnam, 2000), in other words family and close friends. The use of digital tools did not have the purpose of replacing physical social interaction. On the contrary, for the students these tools complemented and/or supplemented interaction with existing social connections. In doing so, the participants maintained their connections while overcoming some communication barriers such as space and time. Digital tools also complemented interaction with weak ties (Putnam, 2000), in this case new university connections. The experience of one participant, whose turning point was being unable to make new friends, exemplifies how digital tools helped her to manage academic demands and social interaction needs: 
When I am in my room I open my Facebook and sometimes I find my friends saying: "oh, come to the study lounge tonight. We miss you. Come to hang out". So I pick up my stuff. I go down there and study with them all night as well as socialising. More socialising goes on when studying but I still get a heap of work done. (VIS-MO)

However, for one student things were still uncertain. He mentioned he did not plan his transition before starting at university. He sought support from the Disability Services unit in the middle of trimester 1 and only because one of his lecturers insisted that he should have a note-taker with him in class. He did not take part in the social meetings for this research in which other participants shared their transition experiences and supported each other. Although this participant perceived he made some progress in trimester 2 as he managed to meet new friends, he was still figuring his transition out:

"[I have had] ups and downs. I am still finding my feet a little bit. Let's see how it goes" (VIS-BL).

As mentioned, all the participants used a range of digital technologies to deal with their transition. One student mentioned that digital tools "make it a lot easier for you to communicate with people, who you need to communicate with, Disability Adviser, Course Coordinator or something like that. It is just easier than going on foot to meet everyone" (VIS-JO). Even VIS-BL, who was not completely settled-in, commented that digital technologies were filling "all the gaps" about study and learning. He pointed out that he could read books and watch videos online "when something was missing in lectures". For him, social media also helped to deal with "big study" during trimester 1 as he browsed the Internet and watched videos on YouTube. Independently of the quality of the information retrieved, it was common among the participants to use the video-streaming platform to search for further information and complement what was taught in the lectures and/or obtain a better understanding of the essay topic they had to write about. The strategies of the participants to support their learning are in line with a tendency among university students in general who engage with a blended learning experience via digital technologies (So \& Brush, 2008).

\subsection{Transition 2.0}

Based on the findings we have come out with the concept of Transition 2.0. Transition 2.0 represents a significant shift from the way transition to university has conventionally been seen by scholars. The evidence from this study shows that students with vision impairments are using digital tools innovatively and creatively to cope with the challenges of their transition experience. Transition 2.0 does not mean a rupture from the conventional approach of Transition 1.0 but an evolution from it. The elements that characterise Transition 1.0 are still present in Transition 2.0. For example, in Transition 2.0 the students are still recipients of specialised support, indeed they still need it, and use assistive technologies to compensate for their vision impairments. The difference is that in Transition 2.0 the students incorporate advanced digital technologies to support work, learning, collaboration and interaction with their peers, so they can manage their transition. As a result, transition to university becomes a collective experience in which the students are able to develop skills and abilities in their own fashion but also in collaboration with others. Thus, Transition 2.0 can be defined as:

The personal and collective experience of the student with vision impairment of making sense of her or his transition to university by sharing, learning, interacting and collaborating via digital technologies, such as social media and mobile devices. In doing so, the student starts acquiring and/or developing the skills, attitudes and knowledge for self-determination that allow her or him to manage the challenges of university life and nurture her or his personal development as a young adult.

In Transition 2.0 digital tools are enablers used to make sense of transition challenges. The behaviour and attitudes of the students are supported by the use of diverse technological tools, not determined by them. 
Thus, the " 2.0 " in Transition 2.0 does not refer to an advanced version of the internet, known as Web 2.0, shaping students' university experience. In Transition 2.0 the students incorporate and adapt according to their personal needs a range of digital tools with which they are familiar. For example, the research findings show that social media applications such as instant messaging and Skype complemented and/or supplemented face-to-face interaction and communication of the students with their families and friends. Similarly, the students also enhanced collaboration with their peers and their own learning via tools such as Facebook, YouTube and Blackboard. In other words, Transition 2.0 centres on the individual and collective experience of the students who used digital technologies to manage their transition.

Transition 2.0 also refers to a generation of young students with vision impairments which has grown up using digital technologies as part of their daily lives. The students are, to a greater or lesser degree, competent users of digital technologies. Several participants described themselves as technology savvy and although a couple of them had technical issues with their new laptops they were already comfortable users of smartphones. Like those students without disabilities, this generation is also familiar with interactive and collaborative applications such as social media which they use to keep socially connected and seek peer support about academic matters. They not only consume but also produce and share their own content online. They adapt tools such as digital cameras and voice recorders to cope with academic challenges in lecture theatres and enjoy the mobility provided by portable devices such as tablets and smartphones when they face unknown physical surroundings, for example.

Based on this explanation, in Table 1, we summarise Transition 1.0 and Transition 2.0.

\begin{tabular}{|c|c|}
\hline Tran & Transition 2.0 \\
\hline $\begin{array}{l}\text { The student faces transition own their own. } \\
\text { Transition is an individual journey. } \\
\text { The student is expected to adjust and/or fit into } \\
\text { the tertiary setting and become an independent } \\
\text { learner. } \\
\text { The student is seen as a passive receptor of } \\
\text { support, which focuses on "normalising" the } \\
\text { student and ameliorating the impact of her or his } \\
\text { impairment. } \\
\text { Assistive technologies play a central role in } \\
\text { compensating for students' impairments at } \\
\text { university. } \\
\text { Other technologies (e.g. the Internet, email, } \\
\text { desktop computers) are used to facilitate access } \\
\text { to information and communication, to arrange } \\
\text { disability support and assist learning. } \\
\text { The student is encouraged and taught self- } \\
\text { determination skills, to mainly manage } \\
\text { academic challenges. }\end{array}$ & $\begin{array}{l}\text { Not only an individual journey but also a } \\
\text { collective one, constructed in collaboration with } \\
\text { peers and supported by a range of digital } \\
\text { technologies. } \\
\text { The student is aware that she or he is still } \\
\text { expected to adjust to university but also requires } \\
\text { the university to share responsibility for her or } \\
\text { his transition. } \\
\text { The student does not ask but demands services } \\
\text { and support to be available to her or him. } \\
\text { The student still uses assistive technologies but } \\
\text { is also familiar and relies on other emerging } \\
\text { technologies. } \\
\text { Like their non-disabled peers, the student is also } \\
\text { an active user of different digital tools (e.g. } \\
\text { mobile devices, social media) and adapts them } \\
\text { for their transition (e.g. digital cameras, digital } \\
\text { audio recorders). } \\
\text { Digital tools are used to manage different } \\
\text { transition issues (e.g. social connections, }\end{array}$ \\
\hline
\end{tabular}




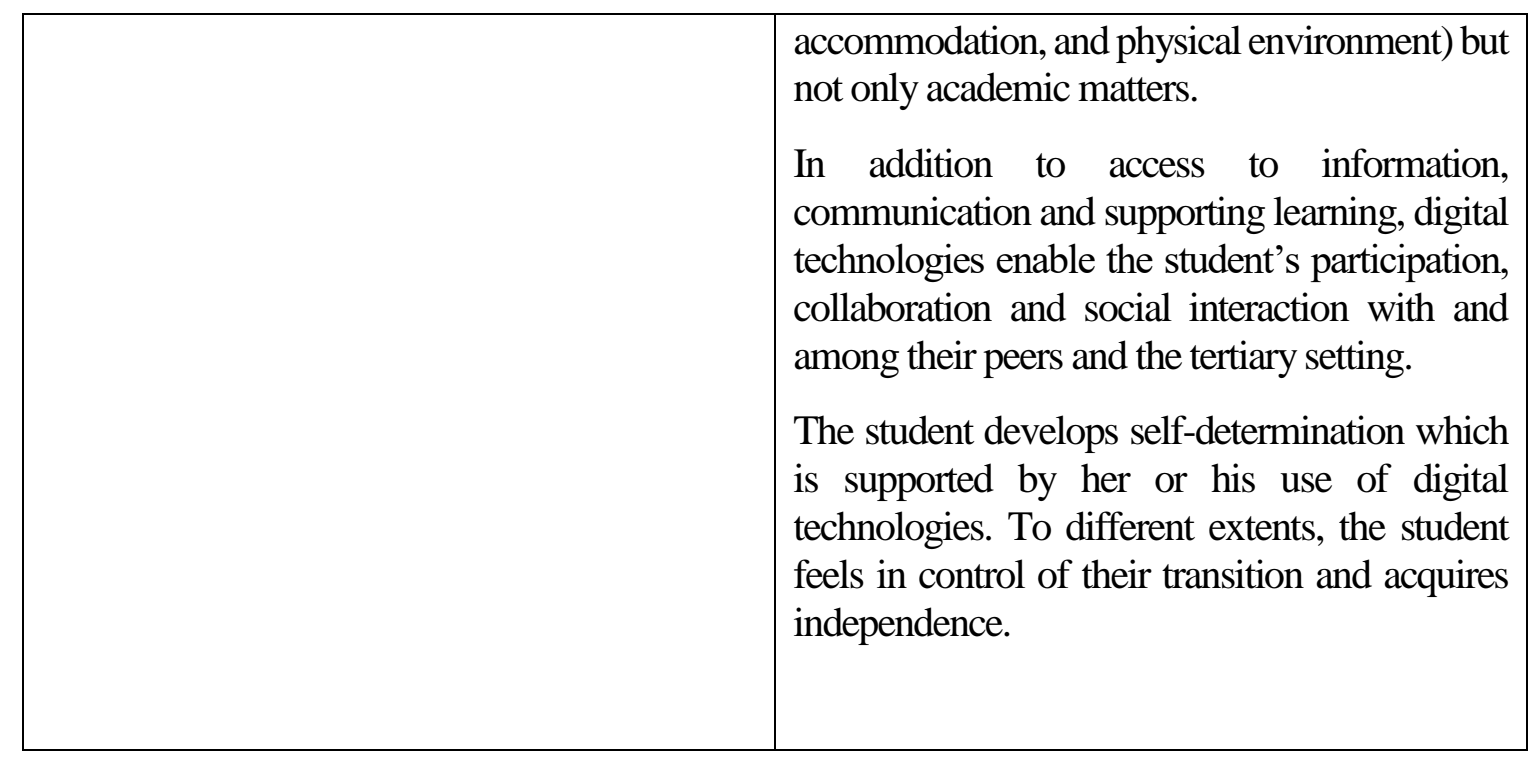

Table 1: Characteristics of Transition 1.0 and Transition 2.0

\subsubsection{The conceptual framework for Transition 2.0}

Figure 1 displays the conceptual framework of Transition 2.0. It outlines that the use and adaptation of digital technologies by students with vision impairments helps them to manage their transition to university. The framework includes the five stages of Transition 2.0: exploring, discovering, coping with, readjusting and settling in. The overlapping ellipses in the framework illustrate that the stages are not independent and separate but ongoing and interconnected. Transition 2.0 begins when young people with vision impairments are still prospective students, well before the start of the academic trimester. The framework mirrors this through a pre-entry stage: exploring - which also takes place during the first weeks at university.

In going through Transition 2.0, the student has to deal with different issues/challenges. These issues affect each student differently. At first glance, the student faces them on her or his own terms, individually. However, to cope with these challenges, she or he also needs their university peers, existing friends and other networks or relationships. Thus, the framework includes the idea of Transition 2.0 as a collective journey as well. Transition 2.0 is not circumscribed by the specific issues that occur within the tertiary setting (e.g. the academic and social systems of the university) as argued by Tinto (1993). On the contrary, they face other additional challenges, such as access to an adequate transport system, the need for family involvement, finding adequate accommodation, the impact of financial concerns and managing the barriers imposed by their own impairment (Bakken \& Obiakor, 2008; Erin \& Wolffe, 1999; Hill \& Taylor, 2004; Hutchinson, Atkinson, \& Orpwood, 1998). This study also found that for these students, getting used to the physical environment of the university, the impact of perceived academic performance and arranging adequate disability support were important aspects to manage.

\section{[Image of conceptual framework here]}

Figure 1: Conceptual framework of Transition 2.0

Along the different stages of Transition 2.0, the student uses and adapts a range of digital technologies to make sense of her or his transition. These tools include those provided by the tertiary setting (e.g. Blackboard) and those used daily by the students (e.g. smartphone). They play different enabling roles, 
from impairment compensation, communication, information, and learning to support arrangement, collaboration, and social connection and participation (Kelly \& Smith, 2011; Pacheco, Yoong, \& Lips, 2017; Presley \& D'Andrea, 2009; Sutcliffe, 1999; van der Geest, van der Meij, \& van Puffelen, 2014). Digital tools are used and adapted according to the particular needs and context of the student's transition experience. As the findings show, apart from being a communication tool, smartphones were used in some cases to take pictures of the whiteboard during lectures in order to support learning and vision compensation. In other cases, these tools were employed for accessing information regarding bus or train timetables. The framework includes these roles of digital technologies and relates them to the transition issues experienced by the student at different stages of Transition 2.0.

As a corollary of actively using and adapting digital tools during the different stages of Transition 2.0, the student develops self-determination. In the framework, a self-determined student with vision impairment has the following characteristics: autonomy/independence, self-regulation, psychological empowerment and self-realisation. These four indicators are based on the work of Wehmeyer and Schwartz (1997) who have extensively studied self-determination in special education. The framework represents a major shift from previous studies. It does not restrict itself to the retention of the student at university and even less her or his adjustment and normalisation to fit into the tertiary setting. In contrast and based on the research findings, the framework suggests that, with the support of digital technologies, the student is able to develop the skills and behaviour to be independent and feel in control of her or his transition and, more importantly, to encourage her or his personal development - as a young adult.

\section{Conclusion}

We need to rethink the transition to university. Digital technologies are ubiquitous in the everyday life of young people, including those with vision impairments, and have already been integrated with the various aspects of higher education. However, research on transition has largely ignored the implications of digital tools for students' experiences during this critical period of change. The literature describes transition to university, which we call Transition 1.0, as an individual experience in which the student is meant to act as an independent learner and adapt to the demands of the tertiary setting. In the case of students with disabilities, the research on technological tools for transition has mostly looked at assistive technologies for impairment compensation and academic adjustment.

This research, however, has found a different scenario. Students with vision impairments also see transition as a collective endeavour and digital tools play an enabling part in that respect. Like their nondisabled peers, these students adapt digital tools innovatively and use them to participate, interact and collaborate with classmates and friends in order to manage different transition challenges, from academic and social connection issues to the physical environment, transportation and their own impairment, among others. Because of the active use and permanent adaptation of these tools, the student is able to develop confidence and self-determination skills and uses them not only to cope with transition but also for her or his personal development as a young adult.

Considering this scenario of the impact of digital tools on transition, this paper has introduced Transition 2.0, as a new paradigm to study and support students with disabilities' transition to higher education. The framework of Transition 2.0 expands current theory as it incorporates in the analysis the role played by tools such as social media and mobile devices throughout its five overlapping stages. The introduction of Transition 2.0 has implications for research and practice. The framework provides a conceptual lens to further study the transition experience of other groups of students with disabilities and can also be adapted to the context of non-disabled students. It also offers a holistic view to understand students with disabilities' retention and engagement in higher education. This study is also timely for disability service providers who may use its insights to inform the development and implementation of blended support programmes and to engage actively with young people with disabilities to understand their transition views and needs. 
We are aware of some limitations of this research. The study is highly contextual as it was conducted in a New Zealand university. Although the findings are based on a rich set of data collected via different techniques and sources, they have to be taken with caution in regard to transferability. We also recommend further research on transition that includes other type of higher education settings (e.g. polytechnics, community colleges). In addition, while this research included students with a number of permanent eye conditions under the umbrella of vision impairment, a limitation is that none of the participants was legally blind. It would be also interesting to investigate the transition experience of those students who pursue a tertiary degree through distance learning instead of on-campus study.

\section{References}

Bakken, J. P., \& Obiakor, F. E. (2008). Transition planning for students with disabilities: What educators and service providers can do. Springfield: Charles C Thomas.

Bardin, J. A., \& Lewis, S. (2008). A survey of the academic engagement of students with visual impairments in general education classes. Journal of Visual Impairment \& Blindness, 102(8), 472-483.

Baskerville, R., \& Myers, M. (2004). Special Issue on action research in information systems: Making IS research relevant to practice: Foreword. MIS Quarterly, 28(3), 329-335.

Bean, J. P. (1980). Dropouts and turnover: The synthesis and test of a causal model of student attrition. Research in Higher Education, 12(2), 155-187.

Belch, H. A. (2004). Retention and students with disabilities. Journal of College Student Retention: Research, Theory and Practice, 6(1), 3-22.

Bell, D. (1999). The coming of the post-industrial society: A venture in social forecasting (Third ed.). New York: Basic Books.

Borg, S. (2001). The research journal: A tool for promoting and understanding researcher development. Language Teaching Research, 5(2), 156-177.

Boyd, D. (2014). It's complicated: The social lives of networked teens. New Haven: Yale University Press.

Bryman, A. (2008). Social research methods (Third ed.). New York: Oxford University Press.

Cabrera, A. F., Nora, A., \& Castaneda, M. B. (1993). College persistence: Structural equations modeling test of an integrated model of student retention. The Journal of Higher Education, 64(2), 123139.

Caton, S., \& Kagan, C. (2007). Comparing transition expectations of young people with moderate learning disabilities with other vulnerable youth and with their non-disabled counterparts. Disability \& Society, 22(5), 473-488.

Creswell, J. W. (2003). Research design: Qualitative, quantitative, and mixed methods approaches (Second ed.). Thousand Oaks: SAGE Publications.

Creswell, J. W. (2007). Qualitative inquiry and research design: Choosing among five approaches (Second ed.). Thousand Oaks: SAGE Publications.

DeAndrea, D. C., Ellison, N. B., LaRose, R., Steinfield, C., \& Fiore, A. (2012). Serious social media: On the use of social media for improving students' adjustment to college. The Internet and Higher Education, 15(1), 15-23. doi: http://dx.doi.org/10.1016/j.iheduc.2011.05.009

Dobransky, K., \& Hargittai, E. (2006). The disability divide in internet access and use. Information, Communication \& Society, 9(3), 313-334.

Duquette, C. (2000). Experiences at university: Perceptions of students with disabilities. Canadian Journal of Higher Education, 30(2), 123-141.

Ebersold, S. (2008). Adapting higher education to the needs of disabled students: Developments, challenges and prospects. In OECD (Ed.), Higher education to 2030 (pp. 221-240). Paris: OECD Publishing.

Ellison, N. B., Steinfield, C., \& Lampe, C. (2007). The benefits of Facebook "friends:" Social capital and college students' use of online social network sites. Journal of Computer-Mediated Communication, 12(4), 1143-1168. 
Erin, J. N., \& Wolffe, K. E. (1999). Transition issues related to students with visual disabilities. Austin: Pro-ed.

Fernández, Á., Rodríguez, M. J., Rodríguez, M. L., \& Martínez, M. J. (2013). Mobile learning technology based on iOS devices to support students with special education needs. Computers \& Education, 61,77-90.

Fowler, C. H., Konrad, M., Walker, A. R., Test, D. W., \& Wood, W. M. (2007). Self-determination interventions' effects on the academic performance of students with developmental disabilities. Education and Training in Developmental Disabilities, 42(3), 270-285.

Getzel, E. E., \& Wehman, P. (Eds.). (2005). Going to college: Expanding opportunities for people with disabilities. Baltimore: P.H. Brookes.

Gikas, J., \& Grant, M. M. (2013). Mobile computing devices in higher education: Student perspectives on learning with cellphones, smartphones \& social media. The Internet and Higher Education, 19, 18-26. doi: http://dx.doi.org/10.1016/j.iheduc.2013.06.002

Goggin, G., \& Newell, C. (2003). Digital divide: The social construction of disability in new media. Oxford: Rowman \& Littlefield Publishers.

Guiffrida, D. (2006). Toward a cultural advancement of Tinto's theory. The Review of Higher Education, 29(4), 451-472.

Hill, N. E., \& Taylor, L. C. (2004). Parental school involvement and children's academic achievement. Current Directions in Psychological Science, 13(4), 161-164. doi: 10.1111/j.09637214.2004.00298.x

Hutchinson, J. O., Atkinson, K., \& Orpwood, J. (1998). Breaking down barriers: Access to further and higher education for visually impaired students. Cheltenham: Stanley Thornes Publishers Ltd.

Janiga, S. J., \& Costenbader, V. (2002). The transition from high school to postsecondary education for students with learning disabilities: A survey of college service coordinators. Journal of Learning Disabilities, 35(5), 463-470.

Kelly, S. M., \& Smith, D. W. (2011). The impact of assistive technology on the educational performance of students with visual impairments: A synthesis of the research. Journal of Visual Impairment \& Blindness, 105(2), 73-83.

Kelly, S. M., \& Wolffe, K. E. (2012). Internet use by transition-aged youths with visual impairments in the United States: Assessing the impact of postsecondary predictors. Journal of Visual Impairment \& Blindness, 106(10), 597-608.

Kennedy, G. E., Judd, T. S., Churchward, A., Gray, K., \& Krause, K.-L. (2008). First year students' experiences with technology: Are they really digital natives? Australasian journal of educational technology, 24(1), 108-122.

King, G., Cathers, T., Brown, E., Specht, J. A., Willoughby, C., Polgar, J. M., . . Havens, L. (2003). Turning points and protective processes in the lives of people with chronic disabilities. Qualitative Health Research, 13(2), 184-206. doi: 10.1177/1049732302239598

Kochhar-Bryant, C., Bassett, D. S., \& Webb, K. W. (2009). Transition to postsecondary education for students with disabilities. Thousand Oaks: Corwin Press.

Kuh, G. D., Cruce, T. M., Shoup, R., Kinzie, J., \& Gonyea, R. M. (2008). Unmasking the effects of student engagement on first-year college grades and persistence. The Journal of Higher Education, 79(5), 540-563.

Liamputtong, P. (2011). Focus group methodology: Principle and practice. London: SAGE Publications. Lincoln, Y. S., \& Guba, E. G. (1985). Naturalistic inquiry. Newbury Park: SAGE Publications.

Lincoln, Y. S., \& Guba, E. G. (1986). But is it rigorous? Trustworthiness and authenticity in naturalistic evaluation. New Directions For Program Evaluation, 1986(30), 73-84. doi: 10.1002/ev.1427

Michaels, C. A., \& McDermott, J. (2003). Assistive technology integration in special education teacher preparation: Program coordinators' perceptions of current attainment and importance. Journal of Special Education Technology, 18(3), 29-44.

Myers, M. D. (2013). Qualitative Research in Business and Management. London: SAGE Publications. 
Neumann, Y., \& Finaly-Neumann, E. (1989). Predicting juniors' and seniors' persistence and attrition: A quality of learning experience approach. The Journal of Experimental Education, 57(2), 129-140.

Pacheco, E., Yoong, P., \& Lips, M. (2017). The role of ICTs in students with vision impairments' transition to university. Paper presented at the International Conference on Information Resources Management - CONF-IRM2017, Santiago, Chile. Retrieved from http://aisel.aisnet.org/confirm2017/34/

Paciello, M. G. (2015). Web accessibility for people with disabilities (Second ed.). Oxford: Focal Press.

Patton, M. Q. (2002). Qualitative research \& evaluation methods (Third ed.). Thousand Oaks: SAGE Publications.

Prensky, M. (2001). Digital natives, digital immigrants Part 1. On the Horizon, 9(5), 1-6. doi: $10.1108 / 10748120110424816$

Presley, I., \& D'Andrea, F. M. (2009). Assistive technology for students who are blind or visually impaired: A guide to assessment. New York: AFB Press.

Putnam, R. D. (2000). Bowling alone: The collapse and revival of American community. New York: Simon \& Schuster.

Risquez, A., \& Sanchez-Garcia, M. (2012). The jury is still out: Psychoemotional support in peer ementoring for transition to university. The Internet and Higher Education, 15(3), 213-221.

Scherer, M. J. (2002). The change in emphasis from people to person: Introduction to the special issue on Assistive Technology. Disability \& Rehabilitation, 24(1-3), 1-4. doi: $10.1080 / 09638280110066262$

Selwyn, N. (2007). The use of computer technology in university teaching and learning: a critical perspective. Journal of computer assisted learning, 23(2), 83-94.

Smithson, J. (2008). Focus groups. In P. Alasuutari, J. Brannen \& L. Bickman (Eds.), The Sage handbook of social research methods (pp. 357-370). London: SAGE Publications.

So, H.-J., \& Brush, T. A. (2008). Student perceptions of collaborative learning, social presence and satisfaction in a blended learning environment: Relationships and critical factors. Computers \& Education, 51(1), 318-336.

Spady, W. (1971). Dropouts from higher education: Toward an empirical model. Interchange, 2(3), 3862. doi: $10.1007 / \mathrm{bf02282469}$

Stumbo, N. J., Martin, J. K., \& Hedrick, B. N. (2009). Assistive technology: Impact on education, employment, and independence of individuals with physical disabilities. Journal of Vocational Rehabilitation, 30(2), 99-110.

Sutcliffe, J. (1999). Information technology. In H. M. S. McCall (Ed.), Visual impairment: Access to education for children and young people (pp. 264-278). London: David Fulton Publishers.

Terenzini, P. T., Springer, L., Yaeger, P. M., Pascarella, E. T., \& Nora, A. (1996). First-generation college students: Characteristics, experiences, and cognitive development. Research in Higher Education, 37(1), 1-22. doi: 10.1007/bf01680039

Tierney, W. G. (1992). An anthropological analysis of student participation in college. The Journal of Higher Education, 63(6), 603-618.

Tinto, V. (1988). Stages of student departure: Reflections on the longitudinal character of student leaving. The Journal of Higher Education, 59(4), 438-455.

Tinto, V. (1993). Leaving college: Rethinking the causes and cures of student attrition (Second ed.). Chicago: University of Chicago Press.

Upcraft, M. L., Gardner, J. N., \& Barefoot, B. O. (Eds.). (2004). Challenging and supporting the firstyear student: A handbook for improving the first year of college. San Francisco: Wiley.

van der Geest, T., van der Meij, H., \& van Puffelen, C. (2014). Self-assessed and actual Internet skills of people with visual impairments. Universal access in the information society, 13(2), 161-174.

Webb, M. (1988). Freshman year retention at three campuses of a large urban community college district: 1983-1986. Community College Journal of Research and Practice, 12(3), 213-242. 
Wehmeyer, M., \& Schwartz, M. (1997). Self-determination and positive adult outcomes: A follow-up study of youth with mental retardation or learning disabilities. Exceptional Children, 63(2), 245255.

Wessel, R., Jones, J., Markle, L., \& Westfall, C. (2009). Retention and graduation of students with disabilities: Facilitating student success. Journal of Postsecondary Education and Disability, 21(3), 116-125.

Zhou, L., Griffin-Shirley, N., Kelley, P., Banda, D. R., Lan, W. Y., Parker, A. T., \& Smith, D. W. (2012). The relationship between computer and internet use and performance on standardized tests by secondary school students with visual impairments. Journal of Visual Impairment \& Blindness, 106(10), 609-621. 